\title{
A supervisão clínico-institucional como dispositivo de mudanças na gestão do trabalho em saúde mental
}

\author{
Ana Kalliny de Sousa Severo(a) \\ Solange L'Abbate ${ }^{(b)}$ \\ Rosana Teresa Onocko Campos ${ }^{(c)}$
}

Severo AKS, L'Abbate S, Onocko Campos RT. Clinical and institutional supervision as a tool for changes in mental health work management. Interface (Botucatu). 2014; 18(50):545-56.

The aim of Brazilian psychiatric reform is to make significant changes in care for people with mental disorders. In this context, clinical and institutional supervision is one of the main qualifying strategies for transforming the methods of work management and clinical care developed in substitutive services. This paper analyzes the experience of clinical and institutional supervision developed within the mental health network in a small municipality in northeastern Brazil. The theoretical and methodological framework of institutional analysis was used. The subjects were employees of a psychosocial care center and a family health support center. The main analysis parameters were the way in which supervision functioned, service management and municipal management. This tool promoted movement towards establishing a team, thereby providing a partnership between services and the municipal manager, and mobilization of workers as subject groups within the field of mental health.

Keywords: Psychiatric reform. Clinical and institutional supervision. Institutional analysis. Work management. Mental health.
A reforma psiquiátrica brasileira objetiva realizar mudanças relevantes no cuidado às pessoas com transtornos mentais. Nesse contexto, a supervisão clínico-institucional é uma das principais estratégias de qualificação para transformar os modos de gestão de trabalho e da clínica desenvolvidos nos serviços substitutivos. Este artigo analisa a experiência de supervisão clínico-institucional desenvolvida junto à rede de saúde mental de um município de pequeno porte do interior do Nordeste. Utilizamos o referencial teórico-metodológico da Análise Institucional. Os sujeitos envolvidos foram os trabalhadores de um Centro de Atenção Psicossocial 1 e do Núcleo de Apoio à Saúde da Família. Os principais analisadores destacados: funcionamento da supervisão, gestão do serviço e gestão municipal. Esse dispositivo promoveu o movimento instituinte junto à equipe, proporcionando uma parceria entre os serviços e o gestor municipal, e a mobilização dos trabalhadores como grupos-sujeitos no campo da saúde mental.

Palavras-chave: Reforma Psiquiátrica. Supervisão clínico-institucional. Análise institucional. Gestão do trabalho. Saúde mental.

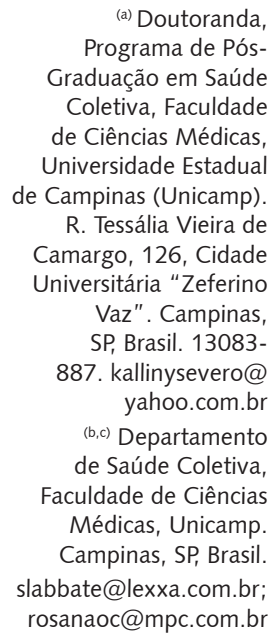

(a) Doutoranda Programa de PósGraduação em Saúde Coletiva, Faculdade de Ciências Médicas, Universidade Estadual de Campinas (Unicamp). R. Tessália Vieira de Camargo, 126, Cidade Universitária "Zeferino Vaz". Campinas, SP, Brasil. 13083887. kallinysevero@ yahoo.com.br

(b,c) Departamento de Saúde Coletiva, Faculdade de Ciências Médicas, Unicamp.

Campinas, SP, Brasil. slabbate@lexxa.com.br; rosanaoc@mpc.com.br 


\section{Introdução: a supervisão clínico-institucional e sua função na política de saúde mental}

A Reforma Psiquiátrica brasileira objetiva a substituição do modelo de atendimento centrado na doença mental, cujo locus central é o hospital psiquiátrico, para um atendimento centrado na existência-sofrimento do usuário, tendo como locus de intervenções o espaço social no qual esse sujeito se insere. Essas mudanças precisam ser acompanhadas de novos modos de cuidado e clínica. Para tanto, reflexões em torno das práticas dos novos serviços substitutivos precisam ser constantes, sendo a supervisão clínico-institucional um dos principais dispositivos adotados na Reforma Psiquiátrica brasileira com essa finalidade. Este artigo analisa a experiência de um processo de supervisão clínico-institucional na rede de Atenção Psicossocial de uma cidade do interior no Nordeste brasileiro, apontando as dificuldades e os desafios aí enfrentados.

\section{A função da supervisão e a problemática da clínica e da gestão na Atenção Psicossocial}

A supervisão clínico-institucional destina-se à discussão das questões clínicas e institucionais dos serviços e da rede de saúde mental. A portaria no 1.174, publicada pelo Ministério da Saúde em 2005, aponta:

Art. $3^{\circ}$ - Definir como supervisão clínico-institucional o trabalho de um profissional de saúde mental externo ao quadro de profissionais dos CAPS, com comprovada habilitação teórica e prática, que trabalhará junto à equipe do serviço durante pelo menos 3 a 4 horas por semana, no sentido de assessorar, discutir e acompanhar o trabalho realizado pela equipe, o projeto terapêutico do serviço, os projetos terapêuticos individuais dos usuários, as questões institucionais e de gestão do CAPS e outras questões relevantes para a qualidade da atenção realizada. $^{1}$ (p. 38)

Essa portaria resultou, sobretudo, de deliberação do I Congresso Brasileiro de Centros de Atenção Psicossocial (CAPS), realizado em 2004, sobre a implantação de supervisão clínico-institucional, e da avaliação nacional dos CAPS (AVALIAR CAPS - BR/2005). Nesta, verificou-se a inexistência de acompanhamento e supervisão clínico-institucional regular na maioria dos CAPS de todos os estados e do Distrito Federal, bem como identificaram-se outras necessidades de qualificação².

O Ministério da Saúde tem apontado para a necessidade de a supervisão ser "clínico-institucional", com a discussão dos casos clínicos associada ao contexto institucional, ao serviço, à rede, à gestão e à política pública, havendo o diálogo necessário entre a dimensão política e a dimensão clínica ${ }^{3}$.

Tais diretrizes do Ministério da Saúde nos instigam a questionar: quais noções de clínica e de gestão têm sido adotadas? Há um movimento de criação de espaços inovadores/instituintes nas práticas de supervisão coerentes com a Atenção Psicossocial ou há uma reprodução do instituído? A singularidade do atendimento nos CAPS demanda a revisão de práticas e conceitos que sustentam o trabalho em saúde mental, a partir da formação acadêmica e de experiências no cotidiano laboral ${ }^{4}$. A saúde mental fundamenta-se em um amplo espectro de conhecimentos sem limites estabelecidos ${ }^{5}$, e quem aí trabalha precisa compreender a complexidade dos problemas e nas intervenções.

Ao discutirmos os projetos terapêuticos e a clínica, entendemos haver uma indissociabilidade deles com a gestão do trabalho. Esta precisa ser problematizada constantemente, visando superar a fragmentação e a hegemonia do paradigma biomédico, presentes ainda hoje em muitos serviços de saúde ${ }^{6,7}$. Além disso, há dois paradigmas em embate nos serviços substitutivos: o paradigma asilar e o psicossocial.

Segundo Costa-Rosa ${ }^{8}$, no modo asilar, os meios de trabalho incluem recursos multiprofissionais, mas não ultrapassam a fragmentação de tarefas e a supervalorização do saber médico. As formas de organização institucional são piramidais, com o fluxo do poder seguindo apenas em um sentido verticalizado e o poder de decisão e de coordenação concentrados no ápice da pirâmide ${ }^{8}$. 
Já o Paradigma Psicossocial propõe que a equipe interprofissional deve caracterizar o meio de trabalho, com a inserção de dispositivos diversificados ${ }^{8}$. A organização do trabalho deve apresentar uma lógica de cooperação entre diferentes profissionais, serviços e gestão-administração. O trabalho da assistência torna-se indissociado do trabalho da gestão, pois os processos decisórios devem perpassar o cotidiano dos serviços, existindo a horizontalização de saberes e de decisões ${ }^{9}$.

Em relação à supervisão, Matumoto et al. ${ }^{10}$ analisam que o trabalho supervisionado remonta à Idade Média, e foi introduzido, nas ciências psicológicas, pela psicanálise. A supervisão foi sofrendo mudanças em sua concepção, metodologia e prática a partir das transformações da grupoterapia.

Coimbra $^{11}$ tece algumas críticas à supervisão, mais particularmente no campo psi, caracterizando-a como modelo autoritário e modelo liberal. No primeiro, o supervisor é aquele que tudo sabe e o supervisando aquele que nada sabe, o que reforça a relação de submissão e onipotência (do psicólogo) que se reproduz nas instituições. Já o segundo é de inspiração humanista, no qual o supervisor afirma ser um igual a seus estagiários, o que escamoteia as relações de poder aí existentes. Na inspiração humanista, "sensibiliza-se, critica-se e questiona-se, desde que seja dentro de certos limites, de determinado território"11 (p. 28). A autora critica a supervisão instituída no sentido de ser uma supervisão, um olhar superior de controle sobre o processo de formação.

Campos $^{6}$ também tece críticas à concepção taylorista que norteia a supervisão em saúde, na qual o supervisor controla e fiscaliza o cumprimento de normas. Já no sentido atribuído pela Saúde Mental, ele seria um agente externo que "se reúne com a equipe para instituir processos de reflexão crítica e de educação permanente" 6 (p. 866). O supervisor assume, assim, a função de ajudar na identificação e enfrentamento de problemas, apoiando mudanças nas equipes de trabalho $0^{6}$. Não deve haver uma valorização demasiada do saber do supervisor, mas, sim, estímulo ao diálogo de todos os saberes da equipe, "fazendo circular o poder entre as diferentes categorias discursivas"12 (p. 93).

Como dispositivo de controle da formação e do processo de trabalho, o termo supervisão vem sofrendo críticas constantes no campo da saúde, com proposições de novas denominações, como inter-visão e co-visão, admitindo que o olhar desse "externo" é um entre outros, que se junta ao olhar da equipe com a proposta de revisitar os caminhos trilhados por ela, de modo a propiciar a percepção de seu modo de sentir, pensar e agir ${ }^{\text {. }}$.

Diante do dilema paradigmático vivenciado nos serviços e das diferentes tradições teórico-técnicas na supervisão, e da escassez de pesquisas sobre o assunto, faz-se necessário haver uma revisão crítica do que seja supervisão em saúde mental no âmbito da Estratégia de Atenção Psicossocial.

\section{Referencial teórico-metodológico}

Adotamos, como perspectiva teórica e metodológica, a Análise Institucional. Rodrigues ${ }^{13}$ situa a $^{2}$ Análise Institucional como movimento originado a partir de conflitos entre intelectuais, políticos e universitários, bem como diversos outros atores sociais. No contexto brasileiro, ela surge nos anos 1970, em departamentos e grupos de pesquisa de universidades brasileiras, havendo uma mistura de conceitos das duas vertentes, a socioanálise e esquizoanálise, junto às outras formas de trabalho grupal ${ }^{14}$.

A tarefa da Análise Institucional é descobrir, desvelar o não dito das instituições, a partir da problematização, do questionamento às instituições ocultas ${ }^{15}$. Desse modo, as instituições formam uma rede social e acabam por unificar e atravessar os indivíduos, que, por meio de sua práxis, mantêm e/ou criam novas (instituinte) ${ }^{15}$.

L'Abbate $^{16}$ explica que Lourau trabalhou com o conceito de instituição a partir das contribuições de Castoriadis sobre a dialética instituinte/instituído e do modelo da dialética hegeliana de afirmação/ negação e negação da negação.

Lourau reconhece três momentos nos quais uma instituição pode ser decomposta: o momento do instituído, ou o estabelecido, considerado o momento da universalidade; o instituinte, ou o acontecimento que não cessa de negar o momento anterior, e que constitui o momento da 
particularidade; e o terceiro momento, o da singularidade, resultado da articulação dialética entre os momentos anteriores, que tensiona a prática dos sujeitos, apontando para uma certa atualização, um "vir-a-ser" que é a institucionalização. ${ }^{16}$ (p. 238, grifos do original)

Além do conceito de instituição, a socioanálise introduz outros conceitos que são considerados regras: a análise da encomenda e da demanda; a autogestão pelo coletivo cliente; a regra do tudodizer; a elucidação da transversalidade; a análise das implicações e a elucidação dos analisadores ${ }^{17}$. Monceau ${ }^{18}$ analisa que, no final de 1980 e nos anos 1990, as modalidades de intervenção em socioanálise diversificaram-se, diferenciando-se da forma mais clássica da intervenção, que ocorria em período curto e com um desenvolvimento rápido.

Desse modo, ele destaca que as regras devem ser consideradas princípios, e adota a denominação de "socioclínica institucional" 19 . Ele enfatiza mais o objeto e as intenções de análise do que as regras. A supervisão analisada neste artigo norteou-se por tais princípios e a intervenção foi considerada, também, como um momento de pesquisa, de construção de um saber sobre o processo de supervisão. Os princípios foram assim caracterizados ${ }^{18}$ :

(a) Análise da encomenda e das demandas: a encomenda escrita constitui o "diagnóstico" de alguém que, investido do poder, faz o pedido de intervenção ao socioanalista ${ }^{20}$, e este deve atentar para a produção das demandas no decorrer do trabalho, sendo essa análise o que sustenta a problematização ${ }^{18}$.

(b) Participação dos sujeitos na abordagem, sob modalidades variáveis, por meio da participação em coleta de informações, aceitação de ser observado ou de participar de sessões de grupo com objetivo analítico ${ }^{18}$. As condições de análise das demandas envolvem a autogestão, com a escolha coletiva dos horários, do número de sessões, das ligações entre as sessões de análise, bem como de outras atividades cotidianas. Com a autogestão, pretende-se revelar o seu contrário, a ordem do estabelecimento. "A diferença entre as duas formas sociais, uma momentânea e analítica, outra permanente e funcional, é um analisador das relações instituídas"17 (p. 103).

No caso da supervisão especificada, a autogestão foi flexibilizada, pois algumas regras de funcionamento foram estabelecidas via edital do Ministério da Saúde.

(a) Trabalho dos analisadores dando acesso às questões que, normalmente, não se expressam: Os analisadores fazem a instituição falar, revelam o não dito $^{21}$. Para Lapassade ${ }^{22}$, trata-se de uma reversão epistemológica, pois é o analisador que faz a análise, e o socioanalista deve validá-los e legitimá-los frente ao grupo participante.

(b) Análise das transformações que se produzem à medida que o trabalho avança: estas expressam, simultaneamente, efeitos e materiais de análise, possibilitando desenvolver, junto aos sujeitos, a consciência dos efeitos da intervenção ${ }^{18}$.

(c) Aplicação das modalidades de restituição que devolvem os resultados provisórios do trabalho aos parceiros de campo: restituição do não dito acerca da instituição e dos pertencimentos institucionais dos diversos membros do grupo, ao longo das sessões socioanalíticas ${ }^{17}$.

(d) Análise das implicações primárias e das implicações secundárias do pesquisador e dos outros participantes (em suas respectivas instituições): "as implicações primárias atualizam-se no dispositivo de análise (e/ou de pesquisa) e as questões locais deste", enquanto as "implicações secundárias são aquelas do interventor/pesquisador na instituição científica, mas também sua relação com a política"18 (p. 6). A aproximação do pesquisador e/ou analista com o campo gera alguns impactos sobre sua própria história e sobre o sistema de poder, que precisam ser constantemente analisados ${ }^{23}$.

(e) Intenção de produção de conhecimentos: o trabalho desenvolvido a partir de uma encomenda leva a uma análise de um problema localizado, que produz dados que precisam ser analisados de forma mais ampla ${ }^{18}$. Para isso, pretendemos construir análises mais abrangentes sobre o dispositivo supervisão e seus efeitos no processo de gestão do trabalho dos serviços tipo CAPS.

(f) Atenção aos contextos e às interferências institucionais nas quais estão envolvidos os pesquisadores e os outros participantes: as instituições que atravessam os sujeitos envolvidos produzem efeitos de conhecimento e de transformação ${ }^{18}$. 
Deve-se atentar para a análise dos vínculos/pertencimentos e das referências positivas ou negativas pelos diversos membros do coletivo em análise ${ }^{17}$, denominada de elucidação das transversalidades, assim definida:

[...] fundamento da função instituinte dos grupamentos, na medida em que toda ação coletiva exige uma perspectiva dialética da autonomia do grupo e dos limites objetivos dessa autonomia. A transversalidade reside no saber e no não-saber do grupamento a respeito de sua polissegmentaridade. É a condição indispensável para passar do grupoobjeto ao grupo-sujeito. ${ }^{24}$ (p. 270)

O grupo torna-se mais sujeito ou menos sujeitado, dependendo de seu coeficiente de transversalidade. O grupo-sujeito tem disposição de gerir a sua relação com as determinações externas e com a própria lei interna do grupo, dentro de algumas possibilidades ${ }^{25}$. Já o grupo sujeitado tende a ser manipulado pelas determinações externas e por sua própria lei interna.

Como dissemos anteriormente, a gestão, a clínica e a supervisão comportam, historicamente, uma relação de saber-poder instituída, que precisa ser constantemente analisada. Nesse sentido, precisa-se investigar o lugar que o analista-pesquisador ocupa que "legitima o instituído, incluindo, aí, o próprio lugar de saber e estatuto de poder do perito-pesquisador" 23 (p. 23).

\section{Caracterização do município e de sua rede de saúde}

O município onde se realizou o processo de supervisão está situado no interior de um estado do Nordeste brasileiro. Segundo o IBGE, esse município tem uma população de 20.354 habitantes e possui uma área geográfica de $513 \mathrm{~m}^{2}$. Sua população urbana se distribui, segundo a área de domicílio, em 17.084 na zona urbana, e 3.270 na zona rural. De acordo com o sexo, tem-se 9.961 homens e 10.393 mulheres na cidade ${ }^{26}$.

A rede de saúde do município é composta por vinte estabelecimentos de saúde. Na Zona urbana há: um hospital municipal, uma maternidade, uma policlínica, nove postos de saúde e seis pontos de apoio, prestando serviços à atenção básica, além do CAPS tipo I do município. Existe ainda, no município, uma equipe do Núcleo de Apoio à Saúde da Família (NASF).

O CAPS I funciona desde 21 de julho de 2006, como referência no atendimento em saúde mental para a população de outros quatro municípios, somando uma população de, aproximadamente, 35.415 habitantes ${ }^{(d)}$.

A equipe do CAPS I era composta, no período da supervisão, por 16 profissionais, a saber: uma psiquiatra, uma psicóloga, uma enfermeira, uma nutricionista, duas assistentes sociais, um farmacêutico, uma auxiliar de enfermagem, duas auxiliares de farmácia, uma artesã, um técnico administrativo e coordenador do serviço e a equipe de apoio (uma chefe de cozinha, uma auxiliar de cozinha, duas pessoas que trabalham na limpeza e uma recepcionista).

O CAPS I funciona de segunda a sexta, das $7 \mathrm{~h}$ às $17 \mathrm{~h}$. Entre as atividades aí desenvolvidas estavam: oficinas terapêuticas, grupos terapêuticos, consultas psicológicas, orientações do serviço social, visitas domiciliares, passeios, entre outros. O serviço atendia 85 usuários divididos entre intensivos - que frequentam os dois turnos e fazem quatro refeições diárias - e semi-intensivos - que ficam apenas durante um turno do dia. A equipe do NASF era composta por dois fisioterapeutas, um psicólogo, um nutricionista e um educador físico. 
A cidade se localiza na quarta região de saúde do estado, cuja cidade principal é distante 282 km da capital. A partir de 2005, nessa região, o Ministério de Saúde começou a implantar uma rede substitutiva ao hospital psiquiátrico, com a formação de rede regional de saúde, culminando na instalação de um dos CAPS III em 2009². Essa região de saúde abrange 25 municípios, com uma população total de mais de 295 mil habitantes.

\section{O processo de supervisão}

Foram realizados, de março de 2011 a fevereiro de 2012, 12 encontros de supervisão, um a cada mês, com carga horária aproximada de seis horas. Nesse artigo, analisamos os oito primeiros encontros de supervisão com as equipes do CAPS e do NASF. De forma sucinta, os temas dos encontros foram:

(a) Primeiro encontro (março/2011) junto à equipe do CAPS: apresentação da proposta e discussão da encomenda e das demandas da equipe;

(b) Segundo encontro (abril/2011) junto à equipe do CAPS: projeto terapêutico singular e equipe de referência;

(c) Terceiro encontro (maio/2011) junto à equipe do CAPS: discussão de projetos terapêuticos singulares dos usuários do CAPS;

(d) Quarto encontro (junho/2011) junto à equipe do CAPS: discussão de caso clínico e projetos terapêuticos singulares;

(e) Quinto encontro (julho/2011) junto às equipes do CAPS e NASF: planejamento das atividades do CAPS e primeiro contato com a equipe NASF;

(f) Sexto encontro (agosto/2011) junto às equipes do CAPS e NASF: papel do NASF na rede de saúde;

(g) Sétimo encontro (setembro/2011) junto às equipes do CAPS e NASF: oficina de planejamento das atividades do CAPS e do NASF;

(h) Oitavo encontro (outubro/2011) junto às equipes do CAPS e NASF: alcoolismo e redução de danos. Articulação serviço-gestão municipal.

Desses encontros participaram cerca de quinze profissionais do CAPS e seis do NASF, com frequência variada, bem como o secretário de saúde do município. Este foi convidado três vezes para supervisão pela coordenação do serviço, e participou de uma reunião, ocasião em que foi convidado conjuntamente pela supervisão e coordenação do serviço, conforme será descrito a seguir.

\section{A encomenda ou como tudo começou}

A encomenda da supervisão surgiu em novembro de 2010, a partir de um convite do consultor do Ministério da Saúde do Nordeste para realizar a seleção para projetos de financiamento para supervisão em saúde mental. Contudo, foi enfatizado que a supervisão seria para a rede de saúde mental, e não apenas restrita ao CAPS.

Esse convite originou-se da publicação do edital Supervisão VI - Ad de $2010^{29}$, no qual consta que o objetivo da supervisão seria possibilitar um espaço de discussão e de "estudo das equipes técnicas dos diversos serviços que compõem a rede de atenção psicossocial, a respeito dos casos clínicos, dos projetos terapêuticos, da dinâmica dos serviços, das articulações com o território onde o CAPS de referência se situa, dos processos de trabalho, da gestão e da clínica na perspectiva intersetorial" 29 (p. 1, grifos nossos). Em dezembro do mesmo ano, foi divulgado o resultado e o projeto foi aprovado.

A encomenda foi dirigida à primeira autora, sendo necessário analisar as demandas da equipe do CAPS. Para tanto, considerou-se as demandas como estando relacionadas "às solicitações, carecimentos e desejos dos participantes do grupo com o qual se vai trabalhar. Mas que, inicialmente afinadas com a encomenda, podem sofrer mudanças no decorrer do processo de intervenção" 20 (p. 200). 
No âmbito deste artigo, selecionou-se, entre as várias dimensões do processo de supervisão, a discussão de alguns analisadores que ocorreram no decorrer dos encontros, uma vez que a análise mais completa da experiência será realizada na tese de doutorado da primeira autora.

\section{Primeiro movimento - a desconfiança}

\section{O funcionamento da supervisão}

Esse analisador emergiu diversas vezes ao longo dos encontros. A partir dele, discutimos, na supervisão, o seu conteúdo e a sua função de acordo com a análise das demandas da equipe.

Durante a discussão da encomenda e das demandas, realizamos uma conversa acerca da proposta e metodologia de trabalho junto à equipe, enfocando, sobretudo, que o processo de supervisão seria realizado a partir de discussões de casos, da análise dos processos de trabalho e englobando diferentes serviços da rede de saúde e intersetorial.

Ao se levantarem as expectativas da equipe sobre o processo de supervisão, foi mencionado que eles estavam sem supervisão há três meses, e que, anteriormente, a supervisão era realizada há três anos por uma mesma profissional, com a fundamentação teórica da psicanálise, centrada no estudo de caso. Algumas questões e dúvidas foram levantadas sobre o referencial teórico usado, se seria válida uma supervisão sem o referencial teórico da psicanálise. De acordo com uma das profissionais do serviço, a psicanálise ou você ama ou você odeia. Os demais trabalhadores se posicionaram, tiraram suas dúvidas, mas não se opuseram a uma supervisão em outra perspectiva teórica e metodológica. No entanto, a questão da supervisão com um norte diferente da psicanálise ressurgiu diversas vezes ao longo do processo de supervisão.

No sexto encontro de avaliação da supervisão, outra trabalhadora explicou, ainda, que a supervisora anterior trabalhava com o transtorno até doer o juízo, com o enfoque na questão sintomatológica. Mas, complementou, comparando uma supervisão e outra, que cada um tem um modo de trabalhar diferente. A psicóloga e uma das assistentes sociais do serviço comentaram, ainda, que sentiam falta de mais discussões de casos clínicos. A psicóloga disse que, por meio da discussão do caso clínico, se consegue avançar bastante no atendimento.

Nesse momento, compartilhamos, num processo de restituição ao grupo, o porquê, nos últimos encontros, de termos trabalhado mais os processos de trabalho. Restituímos, ainda, nossa preocupação em discutir os casos atendidos pela rede de serviços, conforme era previsto na encomenda do edital de supervisão, e apontamos que planejamos e combinamos algumas coisas para os encontros, mas eles tinham demandado, em supervisão, outros diálogos diante do momento que o serviço vinha vivenciando.

Ainda nesse encontro de avaliação, o psicólogo do NAFS explicou que tinha sido um espaço importante, pois os profissionais precisavam da assistência que se estabeleceu, da escuta, de formação, e afirmou que já sentia os efeitos positivos da ação do NASF na saúde mental, pois, em um grupo formado com os usuários, os profissionais perceberam a diminuição do uso de psicotrópicos pela comunidade. Outra profissional dessa equipe explicou, ainda, que tinha sido importante a supervisão para que o NASF entendesse melhor seu papel em relação à rede de saúde mental, e para desconstruir uma relação de medo que, antes, essa profissional tinha em relação às pessoas que sofrem de transtornos mentais.

Percebemos que a equipe CAPS apontava um anseio de saber sobre o transtorno mental, esperando encontrar uma resposta absoluta. Acreditamos que o saber sobre o transtorno deveria ser explorado nas supervisões, mas que seria imprescindível a sua articulação com o território e com a existência do usuário.

Ao mesmo tempo, a equipe demandava falar sobre suas angústias, reapropriar-se de seu cotidiano, analisar suas relações dentro da equipe, com a rede, e com a gestão municipal, como veremos adiante. Essa demanda nos levou a adotar diversos saberes, não centrados no saber do supervisor e nem em uma única especialidade, mas englobando os saberes dos diversos sujeitos envolvidos no processo de supervisão. 
Nessa perspectiva, há, ainda, um movimento instituinte vivenciado nessas equipes em relação à própria supervisão, que aponta para uma apropriação da função do serviço na rede de atendimento de Atenção Psicossocial.

A experiência dos dois modos de viver o momento de supervisão parece ora ser satisfatório, ora sentir falta de algo. Onocko Campos ${ }^{30}$ reflete sobre a experiência da mudança em equipes e afirma que nela está implicada uma escolha, na qual se ganham algumas coisas e perdem-se outras. Resta questionar: de quem foi a escolha? O que sabemos é que a mudança de supervisão era uma entre muitas outras que aquela equipe estava vivendo. Pensamos, ainda, que essas mudanças estiveram profundamente relacionadas à construção da demanda ao longo do processo de supervisão.

\section{Segundo movimento - a análise do nível organizativo}

\section{O analisador gestão do serviço}

O processo de análise sobre a gestão do serviço compreendeu um movimento entre a dificuldade da equipe de assumir as suas decisões (autogestão) e a heterogestão. A análise desse movimento instituído-instituinte se fortaleceu na medida em que houve o processo de restituição acerca dos rumos que a intervenção vinha tomando.

Contextualizando essa discussão, todo o processo de supervisão foi acompanhado de dificuldades vivenciadas na gestão do trabalho em equipe: conflito entre o novo secretário de saúde e a antiga coordenação do serviço, que resultou na saída da coordenação, ficando apenas o administrador do serviço.

O coordenador anterior ocupava a função, praticamente, desde o início do funcionamento do serviço. No primeiro encontro, foi discutido que a coordenação anterior sempre fazia tudo com muita agilidade, de forma dinâmica, o que diminuía a autonomia e possibilidade de participação de outros profissionais do serviço, e, ao mesmo tempo, sobrecarregava a coordenadora. Esse conflito retornou diversas vezes durante a supervisão, influenciando bastante os rumos da intervenção.

Sobre as reuniões de equipe, o atual administrador do serviço, indicado para assumir a coordenação, apontava que os trabalhadores não se dispunham a participar das reuniões, afirmando não haver nada para ser discutido. Então, a equipe inicia um debate sobre quais seriam as características do papel do coordenador e do papel da equipe, e um dos trabalhadores afirma que "um coordenador é como um maestro que vai conduzindo e dando ritmo à equipe, e que isso é importante e que o administrador tem um papel mais burocrático". Nesse sentido, a equipe do CAPS começa a construir coletivamente a função de coordenação do serviço.

Encontramos aí uma dificuldade de o grupo construir estratégias de autogestão, terminando por responsabilizar uma figura central por isso. Onocko Campos ${ }^{30}$ retoma Pichon-Rivière sobre a função do coordenador de manter o grupo triangulando com a tarefa e, nesse sentido, operando. A equipe seria formada por pessoas diferentes, e o que irá diferenciar a gestão tradicional de uma democrática é que, na primeira, o sujeito é chefe, e, na segunda, o sujeito está coordenador, exercendo uma função que pode ser revezada.

Paralelamente a isso, e relacionada à gestão do serviço, vimos ainda a necessidade de se construírem formas de gestão que propiciassem a participação dos usuários e familiares na avaliação das atividades do serviço. Assim, foi proposta (e realizada) a avaliação das atividades do serviço por meio de dispositivos, tais como as assembleias, que propiciaram a expressão dos trabalhadores e usuários do serviço.

Apostar em processos autogestivos, nos quais os coletivos começam a reapropriar-se do seu cotidiano e dos saberes nele envolvido, implica adotar estratégias de horizontalização, entrando em um processo autoanalítico e produzindo sujeitos protagonistas na construção da realidade ${ }^{31}$. 


\section{Terceiro movimento - a análise do nível organizativo}

\section{O analisador gestão municipal}

Nesse movimento, analisaremos a relação que a equipe CAPS mantinha com a gestão municipal, frente às ordens estabelecidas de forma vertical e pouco dialogada, negada por um movimento instituinte de maior diálogo e relação de apoio entre a equipe e a gestão.

Desde os encontros iniciais, a equipe CAPS mostrava-se bastante angustiada diante da mudança do secretário de saúde do município, e, consequentemente, diante das alterações provocadas no CAPS e na rede de saúde. Dentre as dificuldades, foram citadas: a falta de medicação psicotrópica, problemas no transporte de alguns usuários em crise do CAPS I para CAPS III na cidade vizinha, e problemas no estabelecimento de diálogo com o secretário.

Ao longo das discussões, o obstáculo apontado pela equipe para a ausência de diálogo eram as questões políticas e, sobretudo, o receio de represálias. Percebemos que duas questões explicitamente eram postas como justificativas para o silenciamento da equipe: o fato de nenhum trabalhador ser concursado e de que a política em cidade do interior é difícil, como explicado por uma das trabalhadoras. Nesse sentido, a precarização dos vínculos de trabalho articulava-se ao fato de a ocupação dos postos de trabalho estar sendo utilizada, culturalmente, como estratégia de favorecimento/desfavorecimento dos grupos

(e) Isso se identifica com o que Neves $^{32}$ analisa acerca do conjunto das práticas governamentais e gerenciais engendradas nas relações de trabalho ao longo da constituição do Estado brasileiro como caracterizadas pelo patrimonialismo, clientelismo, autoritarismo e paternalismo. as coisas deveriam ser aceitas assim, se não haveria outro modo de agir, tentandr dialogar mais com a gestão central.

Algumas formas de tentar resolver a situação foram pensadas pela equipe: uma vereadora do município foi acionada pela equipe para mediar um diálogo, e a participação do secretário de saúde durante a supervisão para dialogar com a equipe. Assim, ele foi convidado para o momento de restituição e avaliação do trabalho e se disponibilizou, prontamente, a participar do que fosse necessário. Nesse encontro, levantamos o histórico do que tinha acontecido nos primeiros seis meses de supervisão, as dificuldades enfrentadas e, sobretudo, apontamos o movimento instituinte que víamos ser possível em meio àquele conflito, por meio de: reuniões constantes com o secretário, possibilidade de escolha da própria equipe sobre a coordenação (e não por indicação da secretaria de saúde) etc.

O secretário de saúde justificou suas decisões, explicando as dificuldades do último ano, sobretudo financeiras, e evidenciou aquilo que foi possível fazer, quais as ofertas de atendimento que a prefeitura vinha estimulando e quais os avanços já conquistados nesse período.

Além das carências anteriormente colocadas, a equipe tomou a fala e explicou a necessidade de contratação de uma arteterapeuta, e reforçou os problemas apontados. O secretário retomou a palavra, afirmando poder contratar uma arteterapeuta e estar de acordo com o fato de a equipe escolher um novo coordenador, mas solicitou que o comunicassem sobre a decisão. Ele acordou ainda com a equipe que esta planejasse suas atividades, e caso fosse preciso envolver outras secretarias, afirmou a necessidade de ele estar à frente para articular e viabilizar parcerias, apoiando as iniciativas do CAPS. Porém, solicitou que houvesse planejamento das atividades de acordo com as necessidades que os usuários apresentavam.

Nesse analisador, aparecem as dificuldades de negociação com a gestão municipal acerca dos rumos e da autonomia do serviço. Os estilos de gestão e de atendimento da organização CAPS são influenciados por traços culturais 
da administração brasileira, com aspectos que tendem a facilitar a prática de valores nem sempre democráticos e a reprodução de uma lógica corporativista ${ }^{33}$.

Vieira Filho e Nóbrega ${ }^{33}$ apontam que a análise das contradições vivenciadas nos serviços e a possibilidade da desconstrução-reconstrução institucional favorecem o surgimento de caminhos alternativos para as novas práticas de atendimento, com possibilidade de criação e invenção institucional.

A democratização da gestão precisa vir acompanhada de algumas mudanças no perfil dos gestores, com habilidades como: a capacidade de arbitrar, lidando com a dimensão do encontro nos ambientes técnicos e humanos, e de gerir a dimensão histórica e singular de cada situação ${ }^{9}$. Acreditamos que o dispositivo supervisão auxiliou no desenvolvimento de habilidades gestoras que favoreceram a relação de apoio necessária nesse momento singular vivenciado pela equipe.

\section{Algumas considerações: afinal o que esta experiência revela?}

A partir da experiência analisada, percebemos que há processos constantes de institucionalização dos modos de trabalho das equipes e que implicam transformações no modo de fazer supervisão.

Onocko Campos $^{30}$ explica que a supervisão institucional é um dos dispositivos usados para subverter as linhas de poder instituídas nos serviços. Como ferramenta de educação permanente, ela precisa ser um espaço não apenas de resolução, mas de problematização, no qual não se impõem os ideais do supervisor, desprivilegiando o desejo e o conhecimento dos trabalhadores das equipes.

No processo vivenciado, evidencia-se a compreensão do gestor como um apoiador institucional, com ampliação do espaço de diálogo entre os gestores municipais e as equipes da rede de saúde, tentando desconstruir a lógica da gestão verticalizada. O gerente necessita de formação técnica em saúde e em gerência, além de exercer uma função de suporte para os grupos ${ }^{30}$.

Nesse sentido, construímos um modo de fazer supervisão inacabado e que tenta colocar, em análise, o lugar de hierarquia de saber-poder que a supervisão tradicionalmente ocupa. As supervisões devem ser permeáveis à dinâmica do grupo, às características de seu contexto, aos seus saberes e afetos, às experiências vivenciadas pelos usuários. O caráter de construção permanente pode propiciar aumento do coeficiente de transversalidade no grupo, momentos de experimentação dos trabalhadores enquanto grupo-sujeitos.

\section{Colaboradores}

Ana Kalliny de Sousa Severo responsabilizou-se por todas as etapas do trabalho. Solange L'Abbate responsabilizou-se pela revisão teórica do referencial teórico-metodológico. Rosana Teresa Onocko Campos auxiliou na revisão teórica sobre o tema supervisão e nas análises desenvolvidas no artigo.

\section{Referências}

1. Portaria $n^{0} 1.174 / G M$, de 7 de julho de 2005. Destina incentivo financeiro emergencial para o Programa de Qualificação dos Centros de Atenção Psicossocial - CAPS e dá outras providências. Diário Oficial da União. 8 Jul. 2005. Seção I:38.

2. Grigolo T, Delgado PG, Schmidt MB. Avaliar CAPS: um retrato do funcionamento da rede de serviços substitutivos no Brasil. In: Campos FB, Lancetti $A$, organizadores. Saúde e loucura: experiências da reforma psiquiátrica. São Paulo: Hucitec; 2010. v. 9, p. 371-90.

3. Ministério da Saúde. O ofício da supervisão e sua importância para a rede de saúde mental do SUS [Internet]. Brasília (DF); 2007 [acesso 2012 Dez 13]. Disponível em: http:// portal.saude.gov.br/portal/saude/visualizar_texto.cfm?idtxt=31355 
4. Silva $G M$, Beck $C L C$, Figueiredo $A C C$, Prestes $F C$. O processo de trabalho na supervisão clínico-institucional nos Centros de Atenção Psicossocial (CAPS). Rev Latinoam Psicopat Fund. 2012; 15(2):309-22.

5. Amarante PDC. Saúde mental e atenção psicossocial. 2a ed. Rio de Janeiro: Fiocruz; 2007.

6. Campos GWS. O anti-Taylor: sobre a invenção de um método para co-governar instituições de saúde produzindo liberdade e compromisso. Cad Saude Publica. 1998; 4(14):863-70.

7. Campos GWS, organizador. Paidéia e gestão: indicações metodológicas sobre o apoio. In: Saúde Paidéia. São Paulo: Hucitec; 2007. p. 85-102.

8. Costa-Rosa A. O modo psicossocial: um paradigma das práticas substitutivas ao modo asilar. In: Amarante P, organizador. Ensaios, subjetividade e saúde mental. Rio de Janeiro: Fiocruz; 2000. p. 141-68.

9. Santos-Filho SB, Barros MEB, organizadores. Trabalhador da saúde: muito prazer! ljuí Unijuí; 2007.

10. Matumoto $S$, Fortuna $C M$, Mishima SM, Pereira MJB, Domingos NAM. Supervisão de equipes no Programa de Saúde da Família: reflexões acerca do desafio da produção de cuidados. Interface (Botucatu). 2004-2005; 9(16):9-24.

11. Coimbra CMB. A supervisão institucional como intervenção sócio-analítica. Psicol Cienc Prof [Internet]. 1989 [acesso 2014 Maio 20]; 9(1):26-8. Disponível em: http://www.scielo. $\mathrm{br} / \mathrm{pdf} / \mathrm{pcp} / \mathrm{v} 9 \mathrm{n} 1 / 08 . \mathrm{pdf}$

12. Ferigato $S$, Dias $M K$. A supervisão clínico-institucional: um dispositivo teórico-prático para o fortalecimento das redes em saúde mental. In: Dias MK, organizador. Dispositivos de atenção em saúde mental e seus desafios: os impasses na consolidação de uma atenção em rede. Natal: EdUnP; 2013. p. 83-102.

13. Rodrigues HBC. À beira da brecha: uma história da Análise Institucional francesa nos anos 60. In: Amarante P, organizador. Ensaios: subjetividade, saúde mental, sociedade. Rio de Janeiro: Fiocruz; 2000. p. 195-256.

14. Barros RB. Reforma Psiquiátrica Brasileira: resistências e capturas em tempos neoliberais. In: Conselho Federal De Psicologia, organizador. Loucura, ética e política: escritos militantes. São Paulo: Casa do Psicólogo; 2003. p. 196-206.

15. Lourau R. Objeto e método na Análise Institucional. In: Altoé $S$, organizador. René Lourau: analista em tempo integral. São Paulo: Hucitec; 2004. p. 66-86.

16. L'Abbate S. Intervenção e pesquisa qualitativa em Análise Institucional. In: Ceccati JG, Barros NF, Turato $\mathrm{E}$, organizadores. Pesquisa qualitativa em saúde: múltiplos olhares. Campinas: Kompasso; 2005. p. 235-86.

17. Hess R, Savoye A. L'Analyse Institutionnelle (Que sais-je?). Silva ALA, Mourão-Colin LC, tradutoras. 2a ed. Paris: PUF; 1993. cap. IX, p. 97-111.

18. Monceau G. La socio-clinique institutionnelle pour la recherche en éducation et en santé. In: Actes de séminaire Analyse institutionnelle et santé collective; 2010; Niterói (Brasil). Niterói: Universidade Federal Fluminense; 2010. 1 CD-ROM.

19. Monceau G. Pratiques socianalytiques et socio-clinique institutionelle. L' homme Soc. 2003; 147-8:11-33.

20. L'Abbate $S$. Análise institucional e intervenção: breve referência à gênese social e histórica de uma articulação e sua aplicação na Saúde Coletiva. Mnemosine. 2012; 8(1):194-219.

21. Guillier D. Pequena história do analisador dinheiro. Silva ALA, Mourão LC, tradutor. Rev d'Anal Institut. 2001-2002; 5:9-24.

22. Lapassade G. Analyse institutionnelle et socioanalyse. Connexions. 1973; 6:35-57. 
23. Paulon SM. A análise de implicação como ferramenta na pesquisa-intervenção. Psicol Soc. $2005 ; 17(3): 18-25$.

24. Lourau R. A análise institucional. Petrópolis: Vozes; 1970.

25. Guattari F, Rolnik S. Micropolítica: cartografias do desejo. 8a ed. Rio de Janeiro: Vozes; 2005.

26. Instituto Brasileiro de Geografia e Estatística. Censo Demográfico 2010 [Internet]. 2010 [acesso 2011 Nov 5]. Disponível em: http://censo2010.ibge.gov.br/

27. Aragão C, Assis R. Relatório de buscativa em saúde mental no município. Parelhas: Prefeitura Municipal de Parelhas; 2009. [Documento não oficial]

28. Dias MK, Ferigato S, Biegas M. A cultura manicomial além do hospital: o estudo dos cárceres privados em Caicó (RN). In: Lancetti A, Braga Campos $F$, organizadores. Saúde e loucura: experiências da reforma psiquiátrica. São Paulo: Hucitec; 2010. v. 9, p. 73-90.

29. Ministério da Saúde. Edital VI chamada para supervisão clínico-institucional: rede de atenção psicossocial de álcool e outras drogas [Internet]. Brasília (DF); 2010 [acesso 2014 Maio 20]; 8. Disponível em: http://goo.gl/9Vxlxa

30. Onocko Campos R. A gestão: espaço de intervenção, análise e especificidades técnicas. In: Campos GWS, organizador. Saúde Paidéia. São Paulo: Hucitec; 2007. p. 122-52.

31. Baremblitt G. Compêndio de análise institucional e outras correntes: teoria e prática. $5 \mathrm{a}$ ed. Belo Horizonte: Instituto Félix Guattari; 2002.

32. Neves JMA. A face oculta da organização: a microfísica do poder na gestão do trabalho. Porto Alegre: Sulina; 2005.

33. Vieira Filho NG, Nóbrega SM. Atenção psicossocial em saúde mental. Estud Psicol. 2004; 2(9):373-9.

Severo AKS, L'Abbate S, Onocko Campos RT. La supervisión clínico-institucional como dispositivo de cambios en la gestión del trabajo en salud mental. Interface (Botucatu). 2014; 18(50):545-56.

La reforma psiquiátrica brasileña pretende realizar cambios relevantes en el cuidado de las personas con trastornos mentales. En este contexto, la supervisión clínico-institucional es una de las principales estrategias de calificación para transformar los modos de gestión de trabajo y de la clínica, desarrollados en los servicios sustitutivos. Este artículo analiza la experiencia de supervisión clínico-institucional desarrollada con la red de salud mental de un municipio de la región Nordeste. Utilizamos el referencial del Análisis Institucional. Los sujetos fueron los trabajadores de un Centro de Atención Psicosocial I y del Núcleo de Apoyo a la Salud de la Familia. Los principales analizadores fueron: funcionamiento de la supervisión, gestión del servicio y gestión municipal. Ese dispositivo promovió el movimiento instituidor con el equipo, proporcionando una alianza entre los servicios y el gestor municipal y la movilización de los trabajadores como grupos-sujetos en salud mental.

Palabras clave: Reforma Psiquiátrica. Supervisión clínico-institucional. Análisis institucional. Gestión del trabajo. Salud mental.

Recebido em 12/06/13. Aprovado em 08/05/14. 